OPEN ACCESS

Edited by:

Yusuke Sata,

Baker Heart and Diabetes Institute, Australia

Reviewed by:

Keita Saku,

Kyushu University, Japan

Franca Barbic,

Humanitas Research Hospital, Italy

${ }^{*}$ Correspondence:

Arjen Mo

a2.mo@@vu.nl:

mail@arjenmol.net

tORCID:

Arjen Mol

orcid.org/0000-0003-1588-7663

Andrea B. Maier orcid.org/0000-0001-7206-1724

Richard J. A. van Wezel orcid.org/0000-0001-5753-7069

Carel G. M. Meskers orcid.org/0000-0002-5056-5611

Specialty section: This article was submitted to Integrative Physiology,

a section of the journal

Frontiers in Physiology

Received: 07 May 2019

Accepted: 13 February 2020

Published: 03 March 2020

Citation:

Mol A, Maier AB, van Wezel RJA and Meskers CGM (2020) Multimodal

Monitoring of Cardiovascular

Responses to Postural Changes.

Front. Physiol. 11:168.

doi: 10.3389/fphys.2020.00168

\section{Multimodal Monitoring of Cardiovascular Responses to Postural Changes}

\author{
Arjen Mol ${ }^{1,2 * t}$, Andrea B. Maier ${ }^{1,3 \dagger}$, Richard J. A. van Wezel ${ }^{2,4 \dagger}$ and \\ Carel G. M. Meskers ${ }^{1,5+}$
}

1 Department of Human Movement Sciences @AgeAmsterdam, Amsterdam Movement Sciences, Vrije Universiteit Amsterdam, Amsterdam, Netherlands, ${ }^{2}$ Department of Biophysics, Donders Institute for Brain, Cognition and Behaviour, Radboud University, Nijmegen, Netherlands, ${ }^{3}$ Department of Medicine and Aged Care @AgeMelbourne, The Royal Melbourne Hospital, The University of Melbourne, Parkville, VIC, Australia, ${ }^{4}$ Department of Biomedical Signals and Systems, Technical Medical Centre, University of Twente, Enschede, Netherlands, ${ }^{5}$ Department of Rehabilitation Medicine, Amsterdam UMC, Amsterdam Movement Sciences, Vrije Universiteit, Amsterdam, Netherlands

Background: In the poorly understood relationship between orthostatic hypotension and falls, next to blood pressure (BP), baroreflex sensitivity (BRS) and cerebral autoregulation (CAR) may be key measures. The posture- and movement dependency of orthostatic hypotension requires continuous and unobtrusive monitoring. This may be possible using simultaneous photoplethysmography (PPG), electrocardiography (ECG), and near-infrared spectroscopy (NIRS) signal recordings, from which pulse wave velocity (PWV; potentially useful for BP estimation), BRS and CAR can be derived. The PPG, NIRS and PWV signal correlation with BP and BRS/CAR reliability and validity need to be addressed.

Methods: In 34 healthy adults (mean age 25 years, inter quartile range 22-45; 10 female), wrist and finger PPG, ECG, bifrontal NIRS (oxygenated and deoxygenated hemoglobin) and continuous BP were recorded during sit to stand and supine to stand movements. Sixteen participants performed slow and rapid supine to stand movements; eighteen other participants performed a 1-min squat movement. Pulse wave velocity (PWV) was defined as the inverse of the ECG R-peak to PPG pulse delay; PPG, NIRS and PWV signal correlation with BP as their Pearson correlations with mean arterial pressure (MAP) within $30 \mathrm{~s}$ after the postural changes; BRS as inter beat interval drop divided by systolic BP (SBP) drop during the postural changes; CAR as oxygenated hemoglobin drop divided by MAP drop. BRS and CAR were separately computed using measured and estimated (linear regression) BP. BRS/CAR reliability was defined by the intra class correlation between repeats of the same postural change; validity as the Pearson correlation between BRS/CAR values based on measured and estimated BP.

Results: The highest correlation with MAP was found for finger PPG and oxygenated hemoglobin, ranging from 0.75-0.79 (sit to stand), 0.66-0.88 (supine to stand), and 0.82-0.94 (1-min squat). BRS and CAR reliability was highest during the different supine 
to stand movements, ranging from $0.17-0.49(B R S)$ and 0.42-0.75 (CAR); validity was highest during rapid supine to stand movements, 0.54 and 0.79 respectively.

Conclusion: PPG-ECG-NIRS recordings showed high correlation with BP and enabled computation of reliable and valid BRS and CAR estimates, suggesting their potential for continuous unobtrusive monitoring of orthostatic hypotension key measures.

Keywords: baroreceptor reflex, cerebral autoregulation, electrocardiography, near-infrared spectroscopy, orthostatic hypotension

\section{INTRODUCTION}

Orthostatic hypotension $(\mathrm{OH})$, defined as a blood pressure (BP) drop of at least $20 \mathrm{~mm} \mathrm{Hg}$ systolic and/or $>10 \mathrm{~mm}$ Hg diastolic after postural change (Freeman et al., 2011), is highly prevalent in older adults (Cooke et al., 2013; Frewen et al., 2014; Timmermans et al., 2018), whereas the effectiveness of non-pharmacological interventions are limited (De Bruïne et al., 2017). OH may be accompanied by clinical symptoms, e.g., lightheadedness and dizziness (Juraschek et al., 2017, 2018), and is associated with poor clinical outcome such as impaired physical performance (Pasma et al., 2014; de Bruïne et al., 2018; Mol et al., 2018b), falls (Saedon et al., 2016; Mol et al., 2018a), cognition (Iseli et al., 2019), cardiovascular diseases (Verwoert et al., 2008; Ricci et al., 2015) and mortality (Verwoert et al., 2008; Lagro et al., 2012; Rockwood et al., 2012; Ricci et al., 2015; Frith et al., 2016). Sensitivity for the diagnosis of $\mathrm{OH}$ is higher for continuous BP measurement than for intermittent BP measurements after standing up, and continuous BP measurement has shown to be stronger associated with physical performance (Pasma et al., 2014; de Bruïne et al., 2018). However, clinical orthostatic BP measurements do not account for many of the symptoms and falls patients experience at home, due to the time varying and posture- and movement dependent nature of orthostatic BP drop, resulting in a poor reproducibility of the $\mathrm{OH}$ diagnosis (Frith, 2015). Furthermore, the baroreflex (i.e., change in interval between heart beats as a response to $\mathrm{BP}$ changes) and cerebral autoregulation (CAR, i.e., regulation of cerebral blood flow during $\mathrm{BP}$ changes) are mechanisms that potentially attenuate the clinical consequences of $\mathrm{OH}$ and are therefore essential to understand the relationship between $\mathrm{OH}$ and clinical outcome (James and Potter, 1999; Mehagnoul-Schipper et al., 2000; Saint Martin et al., 2013; Tarumi et al., 2014; Ziegler, 2018). BRS and CAR are not addressed during regular clinical BP measurements (Mol et al., 2018c; Zanotto et al., 2018). There is therefore a need for continuous, unobtrusive, simultaneous assessment of orthostatic BP, baroreflex sensitivity (BRS) and CAR, which cannot be performed using the devices currently used in clinical practice.

Elucidation of the relationship between $\mathrm{OH}$ and clinical outcome (i.e., physical performance, cognitive performance and falls) through continuous assessment of BP, BRS and CAR in the home situation may be possible using a combination of noninvasive measurements, encompassing photoplethysmography
(PPG), ECG and near-infrared spectroscopy (NIRS). PPG may enable monitoring BP in superficial arteries, e.g., the radial artery (wrist) or digital artery (finger). PPG amplitude was reported to correlate with BP (Hennig and Patzak, 2013; Lim et al., 2015; Gao et al., 2016; Sun et al., 2016; Ding et al., 2017; Wang et al., 2018). When combined with ECG, PPG can be used to compute pulse wave velocity (PWV), a parameter reflecting both BP, arterial stiffness and arterial vasoconstriction (Salvi, 2017). To assess CAR, cerebral oxygenation measured using NIRS may be used as a proxy for cerebral blood flow (Steiner et al., 2009; Kainerstorfer et al., 2015; Mol et al., 2019).

Prerequisites for clinical application of the BP, BRS and CAR monitor during postural changes are (a) correlation of PPG, NIRS and derived PWV with BP after postural change, to enable BP estimation, (b) good reliability and validity of BRS/CAR estimates and (c) evidence for the potential additional value of BRS estimates assessed during postural change compared to conventional validated BRS measures assessed in rest. In the present proof-of-concept study in a cohort of healthy adults we will address these prerequisites during different types and speeds of postural changes by calculating the correlations between PPG, NIRS and PWV signals, and measured BP; intra class correlation between repeats of postural changes; correlations between BRS/CAR estimates based on estimated and measured BP; and correlations between BRS assessed during postural change and in rest.

\section{MATERIALS AND METHODS}

Thirty-four participants were recruited by oral and written advertisement in a university teaching setting at the Radboud University in Nijmegen, The Netherlands. Sixteen participants were primarily recruited from university students (subgroup 1), while 18 participants were primarily recruited from university employees (subgroup 2). Participants were included if they were younger than 65 years, and had no history of cardiovascular, respiratory or neurological disorders resulting in impaired functioning.

\section{Ethics Statement}

The study was performed in accordance with the Declaration of Helsinki and approved by the Ethics Committee of the Faculty of Science of the Radboud University in Nijmegen. All participants signed informed consent. 


\section{Participant Characteristics}

Information about age, height, weight, handedness, alcohol usage, smoking habits and medication use was obtained from all participants.

\section{Instrumentation}

Two PPG sensors were customized to measure synchronized output signals with a sampling frequency of $1000 \mathrm{~Hz}$ and were applied to the left radial artery (wrist) and digital artery (distal digital finger). The left arm was placed in a sling to minimize differences in height between the PPG measurement location and the heart. A digital tilt meter was attached to the participants' trunk to measure the angle relative to the horizontal plane and to identify the start of postural change. Data recording was performed using a customized application developed in MATLAB R2017b (MathWorks, Natick, MA, United States).

Two PortaLite NIRS sensors (Artinis Medical Systems B.V., Elst, Netherlands; sampling frequency of $50 \mathrm{~Hz}$ ) were applied bilaterally to the forehead, approximately $2 \mathrm{~cm}$ above the eyebrows. Differential pathway factors were estimated based on wavelength and age (Scholkmann and Wolf, 2013). Oxygenated hemoglobin $\left(\mathrm{O}_{2} \mathrm{Hb}\right)$ and deoxygenated hemoglobin $(\mathrm{HHb})$ were computed using the modified Lambert-Beer law (Kocsis et al., 2006). Data recording was performed using Oyxsoft v3 (Artinis Medical Systems B.V., Elst, Netherlands).

A 5-lead ECG and continuous BP and was measured using a Finapres non-invasive hemodynamics monitor (Finapres NOVA, Finapres Medical Systems, Amsterdam, Netherlands), and applied to the left middle finger. This monitor includes a module measuring the height of the finger relative to the heart to enable reconstruction of $\mathrm{BP}$ at heart level from $\mathrm{BP}$ at finger level.

A common analog reference signal was imported into all devices to enable off-line synchronization of the signals. The reference signal consisted of a train of 16 pulses for each minute, each pulse train coding the time from the start of the experiment in minutes. Off-line synchronization and storage, and further analysis of the signals was performed using MATLAB R2017b (MathWorks, Natick, MA, United States).

\section{Protocol}

Participants were asked to void urine before start of the experiment. Room temperature was kept between 20 and $23^{\circ} \mathrm{C}$. Participants were stimulated to relax, instructed not to talk and to limit movements not related to tasks.

To keep the total measurement duration per participant within $2 \mathrm{~h}$, each of the two recruited subgroups underwent a different experimental protocol (Figure 1). Subgroup 1 performed the following postural changes: A (sit to stand, i.e., standing up from sitting position at the preferred speed of the individuals), B (slow supine to stand, i.e., standing up from supine position in approximately $10 \mathrm{~s}$ ) and C (rapid supine to stand, i.e., standing up from supine position in approximately $3 \mathrm{~s}$ ). Subgroup 2 performed postural changes A, D (supine to stand at preferred speed), E (head up tilt, i.e., tilting from supine position to 70-degree tilt in $15 \mathrm{~s}$ without use of leg muscles) and $\mathrm{F}$ (1-min squat, i.e., an isometric leg exercise test increasing BP). Postural changes A-E were preceded by a 5-min resting period [to reach steady state of BP regulation (Frith, 2015)] and followed by a 3-min standing period.

All postural changes were performed in blocks of three repeats per block. Only two repeats per block were performed for postural change $\mathrm{A}$ and $\mathrm{F}$ in subgroup 2 . The sequence of the blocks was randomized to prevent structural influences from preceding postural changes on following postural changes, except for the 1-min squat blocks, which were performed at the end of the protocol as these postural changes might induce fatigue.

\section{Signal Quality Assessment}

PPG, NIRS and BP signals were inspected visually for each repeat of each postural change. Signals not showing a heartbeat for more than $10 \mathrm{~s}$ during baseline (i.e., the $60 \mathrm{~s}$ before testing), more than $10 \mathrm{~s}$ in the first minute after the start of the test or more than $20 \mathrm{~s}$ in minute two and three after the start of the test, were discarded.

\section{Data Preprocessing}

PPG signals were filtered using a $0.05-10 \mathrm{~Hz}$ Butterworth band pass filter to compute PWV (Elgendi, 2012; Akdemir Akar et al., 2013; Sun et al., 2016). The PPG, NIRS and BP signals were resampled at $25 \mathrm{~Hz}$. From these resampled signals, a standardized version (i.e., subtraction of baseline mean and division by baseline standard deviation) and a filtered version (using a 5-s moving average filter) were computed.

\section{Pulse Wave Velocity (PWV) Computation}

Beat-to-beat PWV was computed using the ECG and the PPG signals and defined as the inverse of the time between the R-peak in the ECG to the peak in the first derivative of the PPG signal. Detection of peaks in the first derivative in the PPG signal was performed in two steps, to avoid detecting peaks not corresponding to the upstroke of the PPG wave on the one hand (i.e., a low specificity) and detecting no peaks at all (i.e., a low sensitivity) on the other hand. In the first step, a high specificity, low sensitivity PWV signal was computed, using high peak detection thresholds (i.e., 3 standard deviations of the surrounding $5 \mathrm{~s}$ of PPG signal). In the second step, a high sensitivity, low specificity PWV signal was computed using low peak detection thresholds (i.e., 1.5 standard deviations of the surrounding $5 \mathrm{~s}$ of PPG signal). To compute PWV for as many heartbeats as possible while preventing erroneous PWV calculation, the PWV values in the high sensitivity, low specificity signal exceeding the mean $-3 \mathrm{SD}$ or $+5 \mathrm{SD}$ of the high specificity, low sensitivity signals were discarded and the remaining signal was used for further analysis.

\section{Signal Correlation With BP}

PPG, NIRS, and PWV signal correlation with BP was defined as their correlation with mean arterial pressure (MAP) within $30 \mathrm{~s}$ after each postural change. Filtered signals ( $5 \mathrm{~s}$ moving average window) were used as these were reported to show the most clinically relevant representation of the BP data (van der Velde et al., 2007). The signals were averaged over repeats. 

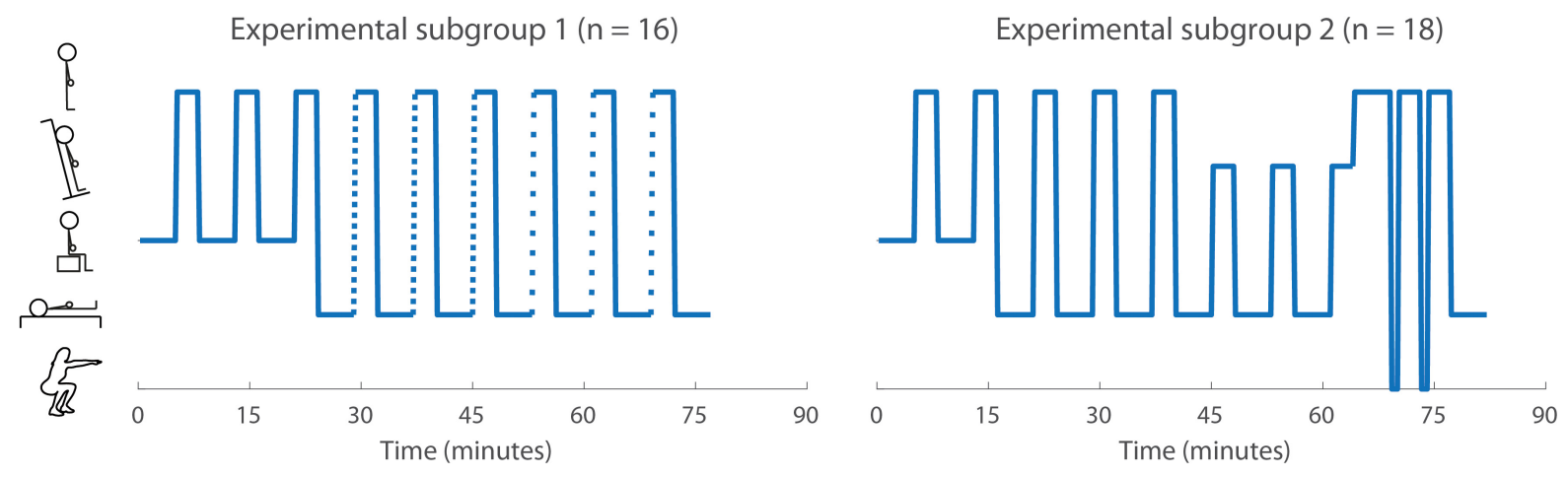

FIGURE 1 | The experimental protocol for both subgroups (adapted from Mol et al., 2019). The symbols on the $y$-axis indicate (from top to bottom): active standing, head-up tilt, sitting, supine, and squat position. Transitions shown as solid lines indicate preferred speed and dashed lines with small and wide gaps indicate rapid and slow transitions, respectively.

\section{Baroreflex Sensitivity (BRS) and Cerebral Autoregulation (CAR)}

BRS was defined as inter beat interval (IBI) drop divided by systolic BP (SBP) drop within 1 min after postural change. CAR was defined as $\mathrm{O}_{2} \mathrm{Hb}$ drop divided by MAP drop within $1 \mathrm{~min}$ after postural change. All computations were performed using the 5-s moving average filtered signals. BRS and CAR values exceeding five times the standard deviation of the other measurements of the same postural change were discarded.

$\mathrm{BRS}$ and CAR were separately computed using measured $\mathrm{BP}$ and estimated BP (Figure 2). BP (both SBP and MAP) estimation was based on the finger PPG and performed for each participant, postural change (except the 1-min squat) and repeat, by using linear regression models with the PPG and BP signals in the interval between 0 and $30 \mathrm{~s}$ as independent and dependent variables, respectively. For a given repeat, PPG and BP signals of the other available repeats of the same subject and postural change were used to compute the regression coefficients. BP was then estimated as: $B P=\beta_{0}+\beta_{1} * P P G$.

The following conventional validated BRS measures were assessed in rest: sequence method BRS and baroreflex effectiveness index (BEI) (Bertinieri et al., 1988; Di Rienzo et al., 2001; Laude et al., 2008; Silva et al., 2019). Sequence method BRS and BEI were computed based on the 5-min resting epochs preceding the sit to stand movements, using the criteria reported by Silva et al. (2019).

\section{Statistical Analysis}

Normally distributed continuous variables were presented using a mean and standard deviation. Variables following other distributions were presented using the median and inter quartile range.

Signal correlation with BP was expressed using Pearson correlation coefficients.

BRS and CAR reliability was defined as their two-way mixed absolute single measure intra class correlation (ICC) between repeats of the same postural change. ICCs between $0-0.40,0.40-$ $0.59,0.60-0.74$, and $0.75-1$ were regarded as poor, fair, good and excellent, respectively (Cicchetti, 1994).
BRS and CAR validity was defined as the Pearson correlation between BRS/CAR estimates based on measured and estimated BP.

The potential additional value of BRS estimates assessed during postural change compared to conventional validated BRS measures assessed in rest was expressed using their Pearson correlations, lower correlations indicating higher potential additional value.

\section{RESULTS}

Table 1 lists the participant characteristics. The median age of the 34 included individuals was 25 years [inter quartile range (IQR) 22-45; 10 female]. Median age of subgroup 1 and 2 was 22.5 years (IQR 21-24) and 37.5 years (26.5-56), respectively, and the number of included female individuals was 4 and 6.

\section{Signals}

\section{Signal Quality Assessment}

After signal quality assessment, at least one repeat for each postural change was available for $31 / 34$ subjects. The proportion of repeats showing good quality data was overall 329/355 (93\%), and ranged among postural changes from $31 / 36$ (86\%; 1-min squat) to $57 / 59$ (97\%; head up tilt). The proportion of signals discarded after visual quality inspection was $8.5 \%$ (wrist PPG), 4.9\% (finger PPG), $1.3 \%$ (NIRS), and 0.6\% (BP). Tables 2, 3 show the available number of repeats per postural change and the number of repeats per signal discarded after data quality assessment, respectively.

\section{Signal Characteristics}

Figure 3 shows the averaged signals during the sit to stand movement and Supplementary Appendix A additionally shows the responses to the supine to stand and head up tilt movements. The signals showed a similar response to sit to stand and supine to stand, and consisted of a temporary drop (BP, $\mathrm{PPG}, \mathrm{O}_{2} \mathrm{Hb}$, and $\mathrm{HHb}$ ) or increase (heart rate and PWV) within $30 \mathrm{~s}$ after standing up, reaching a steady state at $60 \mathrm{~s}$ after standing up. The responses 


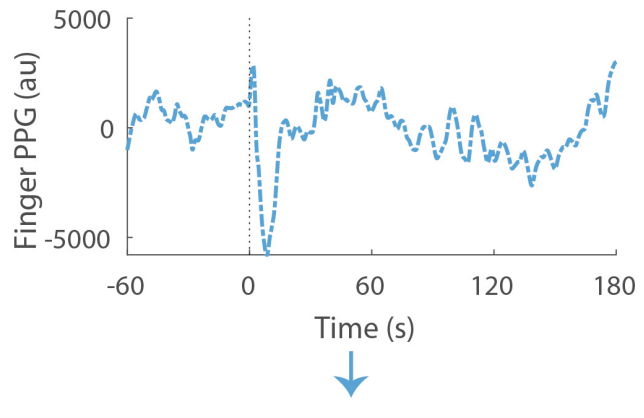

Shifting and scaling of finger PPG signal based on PPG to SBP linear regression coefficients of other repeats
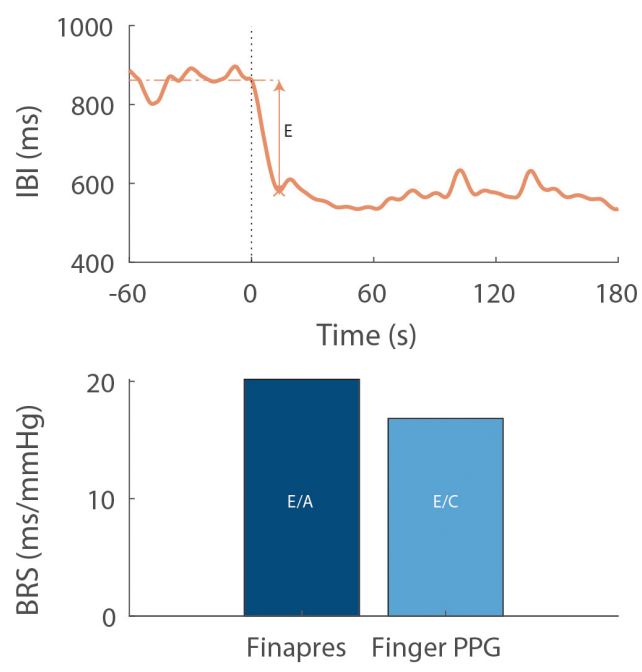
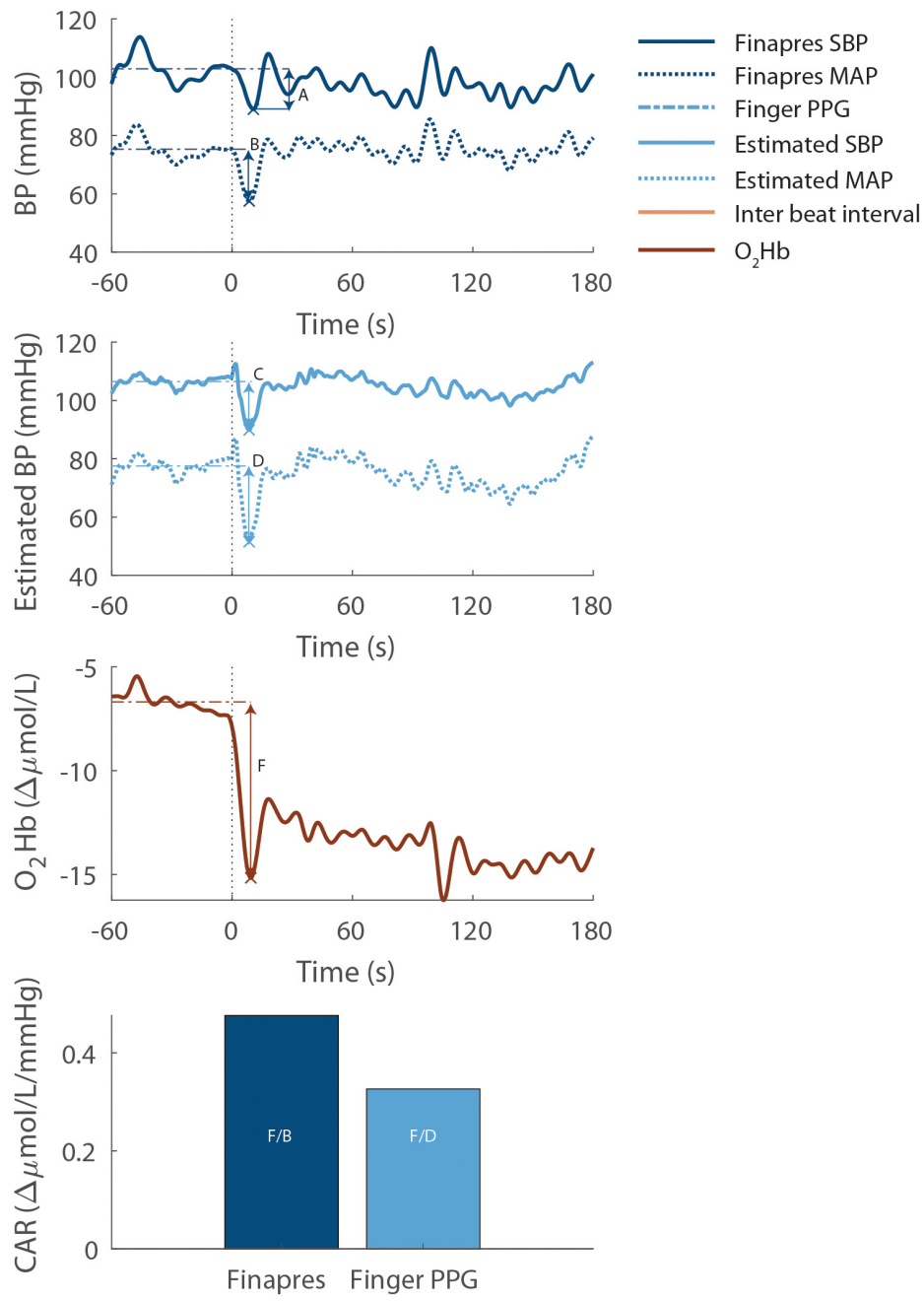

FIGURE 2 | Example computation of baroreflex sensitivity and cerebral autoregulation for the first repeat of supine to stand at preferred speed in one participant. All signals are filtered using a 5-s moving average filter. The vertical dotted lines indicate the start of postural change, the horizontal dashed lines indicate baseline values and the crosses indicate the lowest value after standing up. As indicated in the bottom panels, baroreflex sensitivity is computed as inter beat interval drop (E) divided by the measured (A) or estimated (C) SBP drop. Similarly, cerebral autoregulation is computed as the cerebral oxygenation drop (F) divided by the measured (B) or estimated (D) MAP drop. PPG, photoplethysmography; au, arbitrary units; SBP, systolic blood pressure; IBI, inter beat interval; $\mathrm{O}_{2} \mathrm{Hb}$, cerebral oxygenated hemoglobin. BRS, baroreflex sensitivity; CAR, cerebral autoregulation.

to head up tilt within $30 \mathrm{~s}$ were smaller than the responses to sit to stand and supine to stand movements.

Figure 4 shows the averaged signals during and after a 1-min squat movement. All signals, except $\mathrm{HHb}$ showed an increase during squat. After standing up from squat position, wrist and finger PPG, $\mathrm{O}_{2} \mathrm{Hb}$ and $\mathrm{HHb}$ and $\mathrm{BP}$ showed a sudden drop, heart rate declined slowly and PWV signals increased to rise, reaching a peak at 20-30 s after standing up and declining thereafter. Signal characteristics (means, minima and maxima) after postural changes and during and after the 1-min squat movement are listed in Supplementary Appendices B, C.

\section{Signal Correlation With BP}

Figure 5 shows the PPG, NIRS and PWV signal correlation with BP after postural change. Finger PPG and oxygenated hemoglobin signals showed highest signal correlation with BP, ranging from $0.75-0.79$ (sit to stand), $0.66-0.88$ (supine to stand), and $0.82-0.94$ (1-min squat).

\section{Baroreflex Sensitivity and Cerebral Autoregulation Reliability and Validity}

Figure 6 shows BRS and CAR reliability and validity. BRS and CAR showed the highest ICC between repeats during supine to stand movements, ranging from 0.17 0.49 (BRS) and 0.42-0.75 (CAR). Correlation between BRS/CAR estimates based on measured and estimated BP was highest during rapid supine to stand movements, 0.54 and 0.79 respectively. 
TABLE 1 | Participant characteristics, stratified by subgroups.

\begin{tabular}{|c|c|c|c|c|}
\hline Characteristic & $N$ & All $(n=34)$ & Subgroup $1(n=16)$ & Subgroup $2(n=18)$ \\
\hline Age, years, median [IQR] & 34 & $25[22-45]$ & $22.5[21-24]$ & $37.5[26.5-56.0]$ \\
\hline Male, n (\%) & 34 & $24(70.6)$ & $12(75.0)$ & $12(66.7)$ \\
\hline Height, m, median [IQR] & 34 & $1.80[1.72-1.85]$ & $1.80[1.75-1.86]$ & $1.80[1.67-1.85]$ \\
\hline Weight, kg, median [IQR] & 34 & $70.5[65.8-75.0]$ & $70.5[67.3-74.8]$ & $69.0[63.8-76.5]$ \\
\hline Right-handed, n (\%) & 34 & $29(85.3)$ & $16(100)$ & $13(72.2)$ \\
\hline Current smoking, n (\%) & 34 & $2(5.9)$ & $1(6.3)$ & $1(5.5)$ \\
\hline Excessive alcohol use, $\mathrm{n}(\%)^{\star}$ & 34 & $0(0)$ & $0(0)$ & $0(0)$ \\
\hline Medication use, n (\%) & 34 & $8^{\dagger}(23.5)$ & $3(18.8)$ & $5(27.7)$ \\
\hline Resting HR, bpm, median [IQR] & 34 & $71[66-78]$ & $71[66-77]$ & $71[66-79]$ \\
\hline Resting SBP, mmHg, median [IQR] & 34 & $130[123-140]$ & 126 [122-140] & $131[126-145]$ \\
\hline Resting DBP, mmHg, median [IQR] & 34 & $82[76-87]$ & 79 [73-85] & 83 [78-96] \\
\hline Time needed for sit to stand, s, median [IQR] & 34 & $7.0[5.2-8.0]$ & $6.6[5.3-9.3]$ & $7.0[5.2-8.0]$ \\
\hline Time needed for slow supine to stand, s, median [IQR] & 16 & $15.6[14.1-19.1]$ & $15.6[14.1-19.1]$ & NA \\
\hline Time needed for rapid supine to stand, s, median [IQR] & 16 & $6.7[5.7-8.7]$ & $6.7[5.7-8.7]$ & NA \\
\hline Time needed for supine to stand at preferred speed, s, median [IQR] & 18 & $9.0[6.8-11.4]$ & NA & $9.0[6.8-11.4]$ \\
\hline Time needed for head up tilt, s, median [IQR] & 18 & $16.4[16.1-17.4]$ & NA & $16.4[16.1-17.4]$ \\
\hline
\end{tabular}

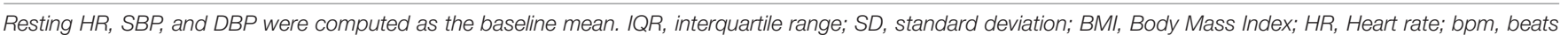

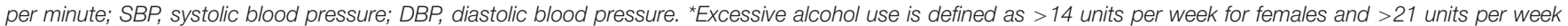

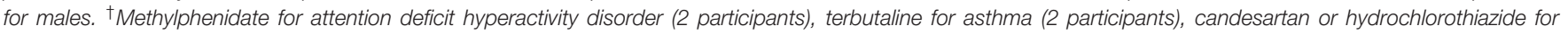
hypertension (2 participants), escitalopram for a mood disorder (1 participant), desloratadine for pollen allergy (1 participant).

TABLE 2 | Data availability, repeats.

\begin{tabular}{lccc}
\hline & \# Participants & $\begin{array}{c}\text { \# Repeats } \\
\text { (\# participants) }\end{array}$ & $\begin{array}{c}\text { Repeats discarded*, } \\
\text { \# repeats } \\
\text { (\# participants) }\end{array}$ \\
\hline $\begin{array}{l}\text { Sit to stand } \\
\text { Slow supine to stand }\end{array}$ & 34 & $3(16), 2(18)$ & $6(5)$ \\
$\begin{array}{l}\text { Supine to stand at } \\
\text { preferred speed }\end{array}$ & 16 & 3 & $5(4)$ \\
Rapid supine to stand & 18 & 3 & $4(3)$ \\
Head up tilt & 18 & 3 & $4(4)$ \\
1-min squat & 18 & 3 & $2(1)$ \\
\end{tabular}

Data availability. Number of participants, number of repeats per participant and availability of extra repeat performed by second observer. *Repeats discarded due to technical problems affecting all signals such as problems with data storage or loss of the reference signal needed for proper synchronization of the signals.

\section{Potential Additional Value of BRS Estimates Assessed During Postural Change}

Figure 7 shows the comparison between BRS estimates assessed during postural change and conventional validated BRS measures assessed in rest. BRS assessed during sit to stand and head up tilt was correlated with sequence BRS ( $r=0.59$ and 0.61 , respectively). Correlations between supine to stand movements and sequence BRS in rest were low $(r=-0.07-0.34)$. All baroreflex measures showed a low correlation with baroreflex effectiveness index $(r=-0.33-0.35)$.

\section{DISCUSSION}

In this proof-of-concept study in a cohort of healthy adults we found that combined PPG, ECG and NIRS signal recordings
TABLE 3 | Data availability, signals.

\begin{tabular}{lcccc}
\hline & Wrist PPG & Finger PPG & NIRS & BP \\
\hline Sit to stand & $8(5)$ & $4(3)$ & 0 & 0 \\
Slow supine to stand & $10(5)$ & $5(2)$ & 0 & $1(1)$ \\
Supine to stand at preferred speed & $1(1)$ & $2(2)$ & 0 & 0 \\
Rapid supine to stand & $8(6)$ & $3(2)$ & $2(1)$ & $1(1)$ \\
Head up tilt & 0 & 0 & 0 & 0 \\
1-min squat & $1(1)$ & $2(2)$ & $2(2)$ & 0 \\
\hline
\end{tabular}

The table lists the number of discarded repeats per signal, stratified by test condition. The values in parentheses indicates the number of participants for whom one or more repeats per signals were discarded.

to estimate BP, baroreflex sensitivity (BRS) and cerebral autoregulation (CAR) during various postural changes showed high signal correlations with measured BP, particularly for finger PPG and NIRS derived oxygenated hemoglobin (correlations ranging from 0.66 to 0.94). Furthermore, we found that BRS was of poor to fair reliability and CAR was of fair to excellent reliability during the supine to stand movements. Correlations between BRS/CAR estimates based on estimated and measured BP were 0.54 and 0.79, respectively. Correlations between BRS estimates assessed during postural change and conventional validated BRS measures assessed in rest were particularly low for supine to stand movements, indicating the potential additional value of the BRS estimates assessed during these postural changes. These results suggest the potential clinical value of these techniques for continuous and unobtrusive monitoring of BP, BRS and CAR as key measures of $\mathrm{OH}$.

To the best of our knowledge, this is the first study proposing and assessing a non-invasive technique that might be used for 


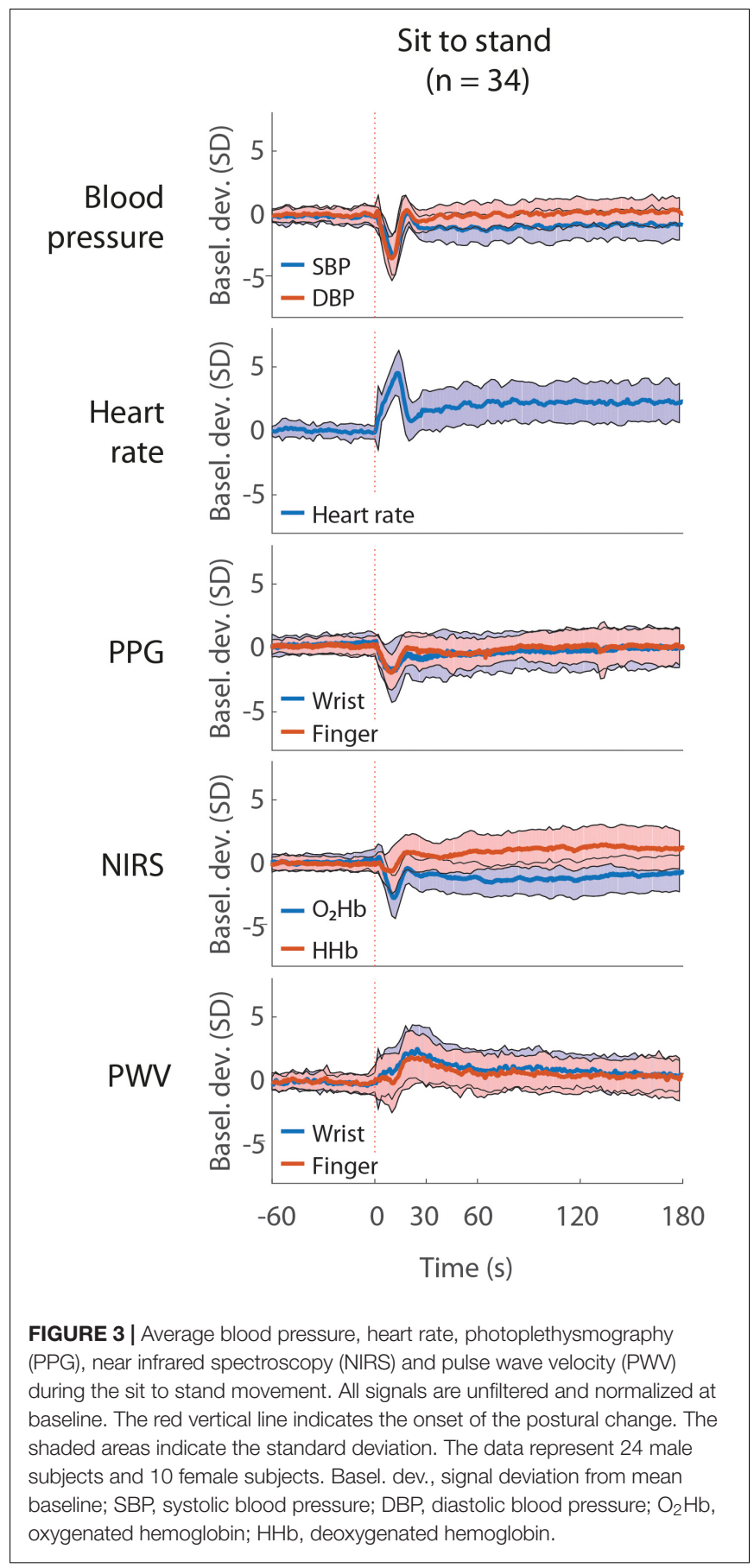

continuous monitoring of posture-related BP, BRS and CAR in patients with $\mathrm{OH}$. Results on sensitivity and reliability of NIRS parameters in a subpopulation of this study $(n=15)$ were published before (Mol et al., 2019). Other previous research focused on specific aspects, such as PPG-based BP estimation (Chen et al., 2012; Sun et al., 2016), cerebral oxygenation changes during standing up (Mehagnoul-Schipper et al., 2000, 2001; van Lieshout et al., 2001) and posture related PWV changes (Foo and Lim, 2006), but never assessed a combined ambulatory technique for BRS and CAR monitoring.

\section{Signal Correlation With BP}

The high correlation with BP found for finger PPG indicates that this signal might be used for continuous BP estimation during postural change. The high correlation of $\mathrm{O}_{2} \mathrm{Hb}$ with $\mathrm{BP}$ was not expected, as $\mathrm{O}_{2} \mathrm{Hb}$ is not only determined by $\mathrm{BP}$, but also by CAR (Steiner et al., 2009; Kainerstorfer et al., 2015), which may act as a high-pass filter (Tarumi and Zhang, 2018), and cerebral microcirculation (Krakow et al., 2000). The results of the present study indicate that $\mathrm{BP}$ is a relatively large contributor to cerebral oxygenation.

Finger PWV correlated well with BP during the rapid supine to stand movement, but not during other postural changes, potentially due to the fact that $\mathrm{BP}$ drop is largest during rapid supine to stand. However, PWV in theory also reflects arterial stiffness and arterial vasoconstriction, which are of interest in patients with $\mathrm{OH}$ (Salvi, 2017). The association of PWV with arterial stiffness and arterial vasoconstriction was not addressed in the present study, but should be investigated in future studies by assessing the association of PWV with carotid intima-media thickness, as a measure of vessel stiffness (Koivistoinen et al., 2007; Torjesen et al., 2017; Ikonomidis et al., 2019), and by measuring PWV during hand grip exercise, which influences vascular sympathetic outflow and thereby vasoconstriction (Kamiya et al., 2001; Jarvis et al., 2011). If PWV can be demonstrated to be a good measure of vessel stiffness, it can potentially be used to differentiate between impaired baroreflex sensitivity from increased vessel stiffness and other (e.g., neural) causes.

\section{Baroreflex Sensitivity and Cerebral Autoregulation}

BRS reliability was rather low, which may imply that more than three rapid supine to stand repetitions may be necessary to cancel out noise. CAR reliability and validity was higher compared to BRS reliability and validity, which may be explained by the many factors (e.g., emotions, mood, respiration) that influence inter beat interval (Fatisson et al., 2016), which is used to compute BRS, but not CAR.

BRS and CAR showed highest validity when assessed during rapid supine to stand movement, potentially because PPG-ECGNIRS signal to noise ratio is highest during this postural change.

BRS and CAR computation depends on a good BP estimation, for which an accurate model is necessary. In this study, simple linear regression models were used for to this end to provide first evidence that BP can be estimated from finger PPG signals. However, substantial inter- and intra-individual variation of the regression betas was observed, which implies frequent calibration is necessary to obtain accurate BP estimations. As this is impractical for the goal of continuous estimation of BP, BRS and CAR, more robust models should be developed to estimate BP from PPG-ECG-NIRS data, which may also incorporate heart rate and PWV signals. This could be performed by training neural networks, warranting further research.

Correlations between BRS estimates assessed during postural change and conventional validated BRS measures assessed in rest were rather low, indicating the potential additional value of the 


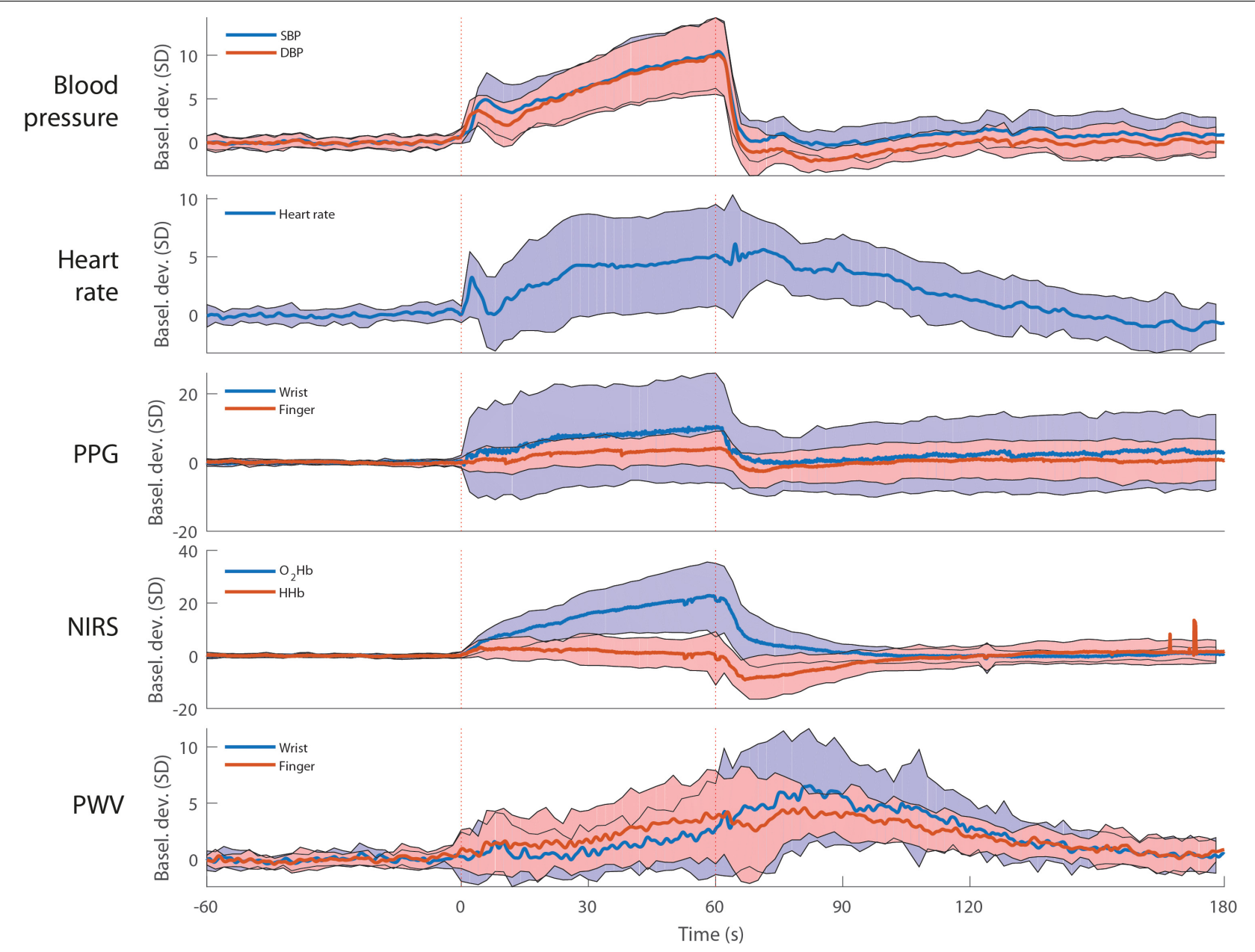

FIGURE 4 | Average blood pressure, heart rate, photoplethysmography (PPG), near infrared spectroscopy (NIRS) and pulse wave velocity (PWV) during 1-min squat movement. All signals are unfiltered and standardized at baseline. The red dotted vertical lines indicate the onset and end of 1-min squat movement. The shaded areas indicate the standard deviation. The data represent 12 male subjects and 6 female subjects. $\mathrm{N}=18 . \mathrm{O}_{2} \mathrm{Hb}$, oxygenated hemoglobin; HHb, deoxygenated hemoglobin.

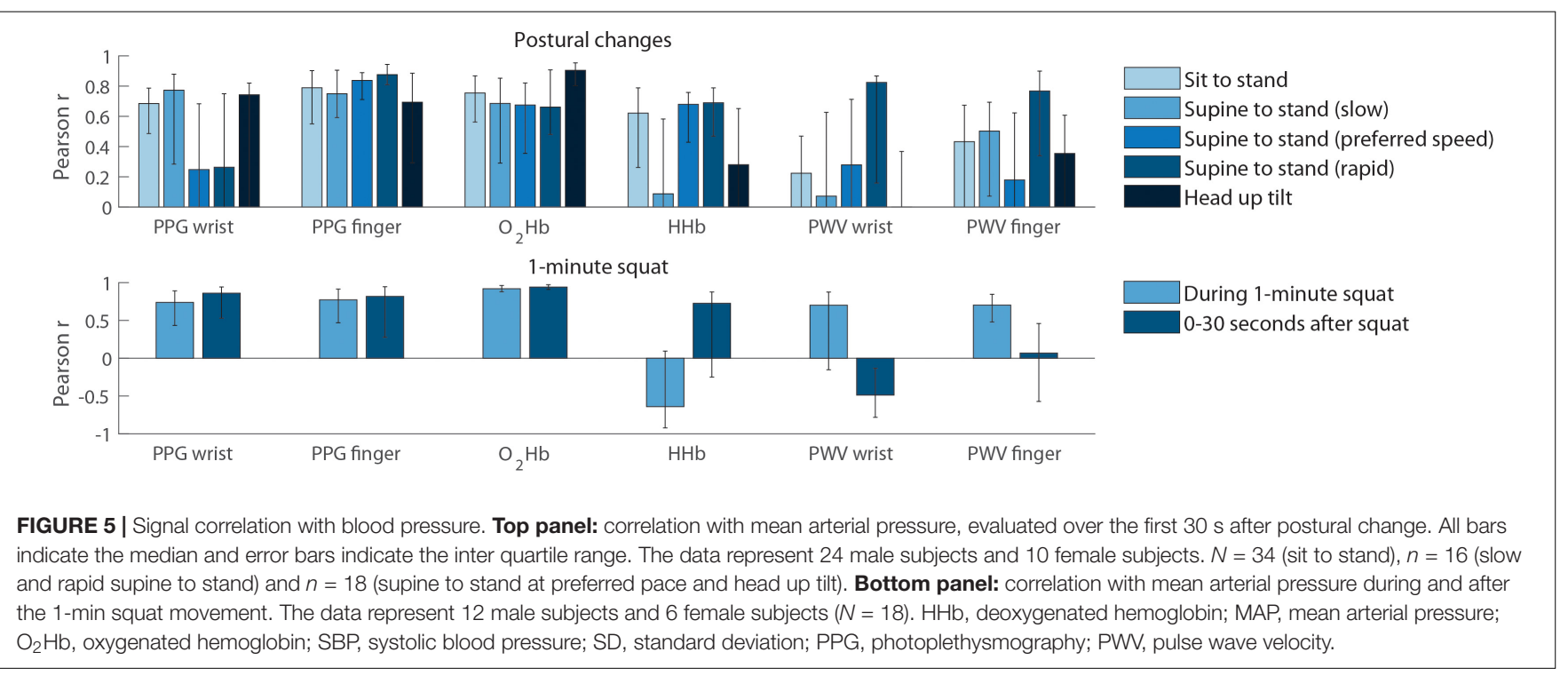




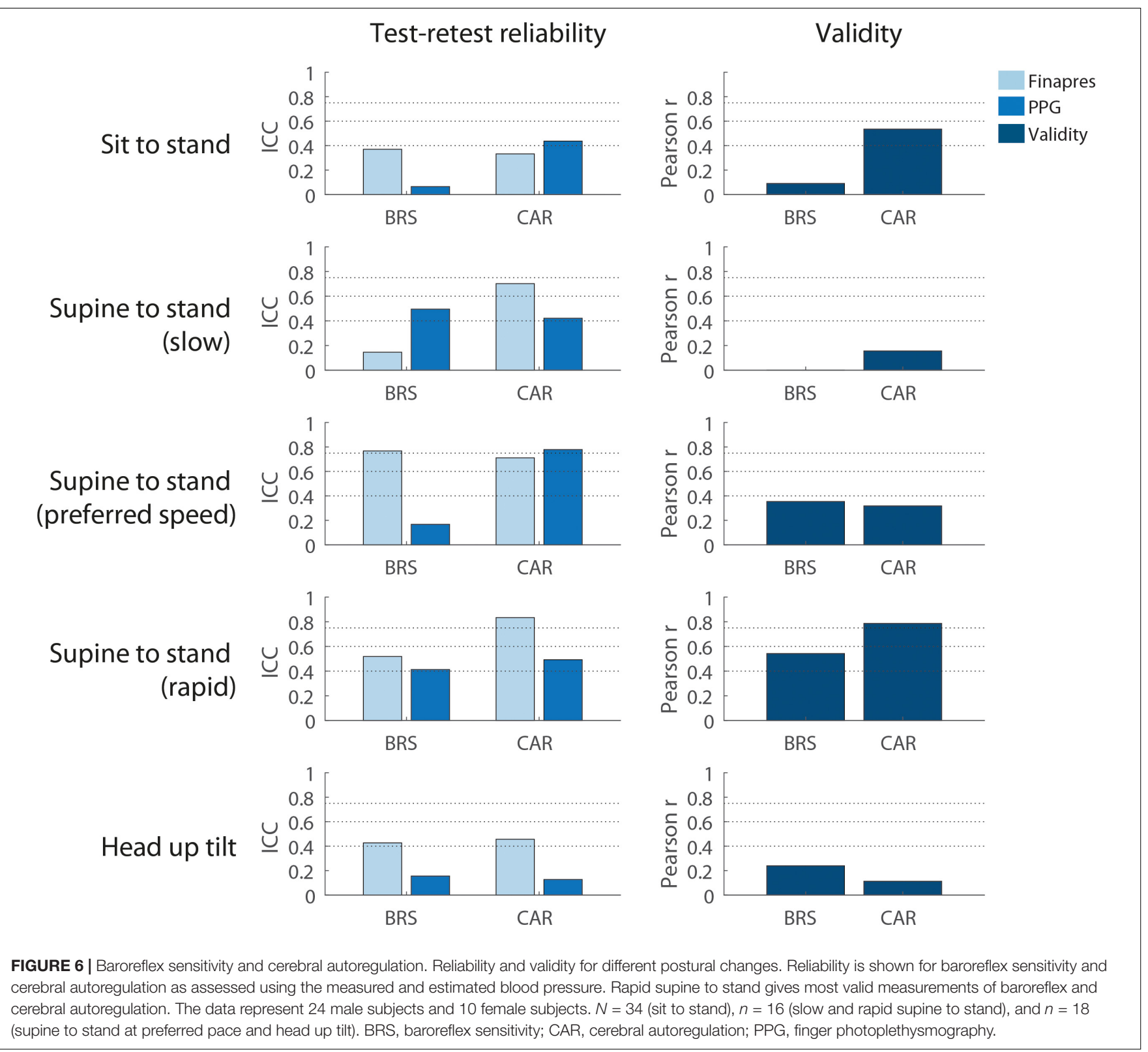

BRS estimates assessed during these postural changes. The low correlation may be explained by the non-linear nature of the baroreflex, implying that a BP variation increase with a certain factor is not necessarily followed by a change in inter beat interval variation increase with the same factor (Di Rienzo et al., 2009).

In the present study, BRS was defined as the inter beat interval drop divided by the SBP drop after standing up. The clinical value of this BRS measure needs to be further established by addressing its association with clinical phenotype, e.g., age, presence of orthostatic symptoms, and physical and cognitive performance. Furthermore, the underlying physiology should be elucidated by simultaneous measurements of muscle sympathetic nerve activity (Marchi et al., 2016). A proper functioning baroreflex characterized by inter signal coupling of heart rate, BP and muscle sympathetic nerve activity may be particularly related to clinical phenotype (Barbic et al., 2019). Development of barocontrol models is needed to further disentangle different components contributing to the baroreflex (Porta et al., 2012).

As the NIRS-based measure of CAR used in the present study may apart from cerebral blood flow also be influenced by cerebral microcirculation, further external validation of this CAR measure using cerebral blood flow measurements should be performed in further research, as well as its association with clinical phenotype.

\section{Accuracy of the BP Measurements Used as a Gold Standard}

In this study, continuously and non-invasively measured peripheral BP was used to estimate central (aortic) BP, as in other studies (Pinna et al., 2000; Dell'Oro et al., 2018; 

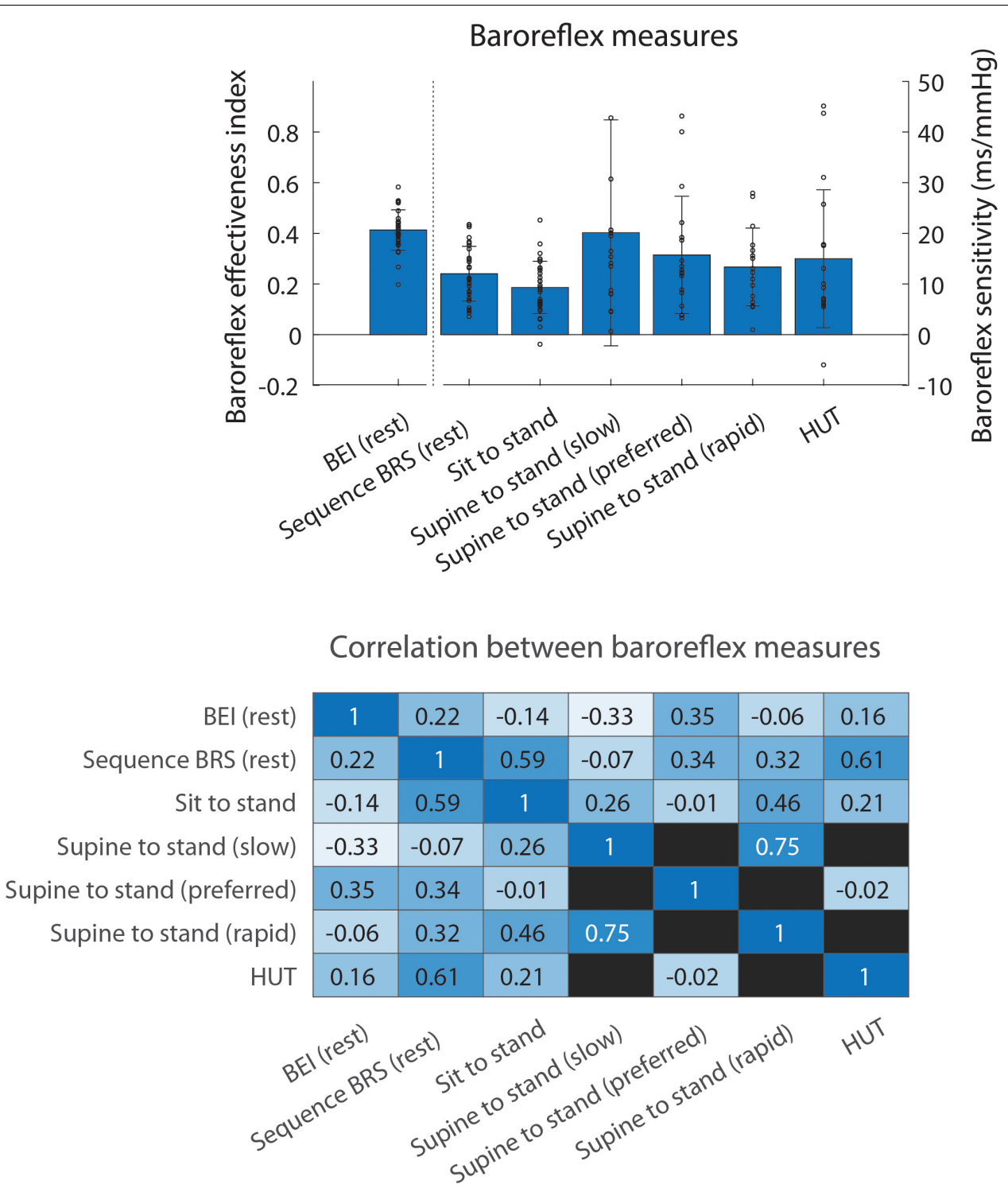

FIGURE 7 | Comparison between baroreflex measures. Bars in the top panel show the mean of each baroreflex measure, error bars indicating the standard deviation and small circles the data points corresponding to individual subjects. The bottom panel shows the Pearson correlation coefficient of the correlation between the different measures. Empty squares indicate that the two baroreflex measures were not available for the same individuals. BEl, baroreflex effectiveness index; BRS, baroreflex sensitivity; HUT, head up tilt.

Fonkoue et al., 2019; Lázaro et al., 2019; Simpson et al., 2019; Wakeham et al., 2019). Continuously and non-invasively measured peripheral BP was demonstrated to give a good approximation of intra-arterial radial BP in different clinical populations (Pinna et al., 2000; Ameloot et al., 2014; Smolle et al., 2015; Berkelmans et al., 2017).

BP drop after the head up tilt movement was smaller compared BP drop after the active stand movements. This is accordance with results reported in a previous study and may be due to a temporary muscle artery vasodilation during active standing up in contrast to passive tilt, decreasing BP (van Wijnen et al., 2017). This effect counteracts the BP increasing effect of muscle use during standing up through increased venous return and seems to outweigh it in the present and a previous study (van Wijnen et al., 2017).

\section{Strength and Limitations}

The strength of this study is that it systematically assesses the PPG, NIRS, and PWV correlation with BP after postural change and the reliability and validity of the derived BRS and CAR estimates.

The generalizability of this study to the proposed target group of older adults with $\mathrm{OH}$ is limited due to the young age of the investigated population. Though the investigated population was relatively healthy, some individuals in the investigated population used drugs affecting the cardiovascular system. Together with the 
relative underrepresentation of female participants (29.4\%), this limits the representativeness of the results for healthy adults. The difference in median age between the subgroups was rather large due to recruitment differences, which limits the comparability of the subgroups. This should be taken into account when comparing the results from two postural changes executed by the two different subgroups, e.g., the rapid supine to stand and supine to stand at preferred speed movements.

The absence of cerebral blood flow measurements as a gold standard for CAR measurements and the fact that $7 \%$ of the trials had to be discarded during some repeats due to technical problems or poor signal quality are limitations of this study.

Correlation of finger and wrist PPG with BP was computed while the arm was kept at heart height using a sling, which is a limitation for ambulatory applicability. Future experiments should be independent of this design by correcting PPG based $\mathrm{BP}$ estimations for the difference in height between heart and PPG measurement site. This height difference therefore has to be measured separately.

The currently proposed model to estimate BP based on finger PPG is dependent on regular calibration of the data, which is an issue to be addressed in further research.

\section{Clinical Perspectives and Future Directions}

Clinical application of the PPG-ECG-NIRS monitor requires several additional steps, i.e., making the separate sensors entirely wireless, improving the BP estimation algorithms, making BP estimation independent of finger height relative to the heart and further validation of the BRS and CAR estimates in a clinical setting. When these requirements are met, PPG-ECGNIRS could be applied in patients with impaired mobility or falls, as suspected due to inadequate BP regulation. The PPGECG-NIRS monitor should provide a personal risk profile of BP regulation during standing up, which may enable clinicians to personalize treatment, e.g., giving advice on lifestyle changes or revising medication.

Further research should address the association of the investigated parameters with healthy aging and the occurrence of clinical orthostatic symptoms, mobility impairment and falls. It should further address the external validity of the CAR estimates using cerebral blood flow velocity measurements during postural changes. More robust models should be developed to be able to continuously monitor BP, BRS and CAR from PPG-ECG-NIRS signal recordings without the need for frequent calibration.

\section{REFERENCES}

Akdemir Akar, S., Kara, S., Latifoglu, F., and Bilgiç, V. (2013). Spectral analysis of photoplethysmographic signals: the importance of preprocessing. Biomed. Signal Process. Control. 8, 16-22. doi: 10.1016/j.bspc.2012.04.002

Ameloot, K., Van De Vijver, K., Van Regenmortel, N., De Laet, I., Schoonheydt, K., Dits, H., et al. (2014). Validation study of Nexfin(R) continuous non-invasive blood pressure monitoring in critically ill adult patients. Minerva Anestesiol. 80, 1294-1301.

Barbic, F., Heusser, K., Minonzio, M., Shiffer, D., Cairo, B., Tank, J., et al. (2019). Effects of prolonged head-down bed rest on cardiac and vascular baroreceptor

\section{CONCLUSION}

PPG and NIRS signals correlated with BP in healthy adults, enabling BP estimation. The BRS and CAR estimates derived from the PPG-ECG-NIRS signals were reliable and valid during supine to stand movements. This study provides evidence of the potential additional value of BRS estimates assessed during postural change compared to conventional validated BRS measures assessed in rest. The results suggest the potential clinical applicability of the PPG-ECG-NIRS signal recordings for continuous unobtrusive monitoring of $\mathrm{BP}, \mathrm{BRS}$, and CAR.

\section{DATA AVAILABILITY STATEMENT}

All data and analysis scripts are available via the following link: http://hdl.handle.net/11633/di.dcn.DSC_62002451_01_149.

\section{AUTHOR CONTRIBUTIONS}

AM, ABM, RW, and CM conceived of the presented idea and designed the study. AM performed the data collection, performed the analysis, and took the lead in writing the manuscript. All authors discussed the results, contributed to the final manuscript, approved the final version of the manuscript and agreed to be accountable for the study, and designated as authors qualify for authorship, and all those who qualify for authorship are listed.

\section{FUNDING}

This study was supported by a grant from the Applied and Engineering Science domain (TTW) of the Netherlands Organization of Scientific Research (NWO): NeuroCIMTBarocontrol (grant no. 14901).

\section{SUPPLEMENTARY MATERIAL}

The Supplementary Material for this article can be found online at: https://www.frontiersin.org/articles/10.3389/fphys. 2020.00168/full\#supplementary-material

modulation and orthostatic tolerance in healthy individuals. Front. Physiol. 10:1061. doi: 10.3389/fphys.2019.01061

Berkelmans, G. F. N., Kuipers, S., Westerhof, B. E., Spoelstra-de Man, A. M. E., and Smulders, Y. M. (2017). Comparing volume-clamp method and intra-arterial blood pressure measurements in patients with atrial fibrillation admitted to the intensive or medium care unit. J. Clin. Monit. Comput. 32, 1-8. doi: 10.1007/ s10877-017-0044-9

Bertinieri, G., Di Rienzo, M., Cavallazzi, A., Ferrari, A. U., Pedotti, A., and Mancia, G. (1988). Evaluation of baroreceptor reflex by blood pressure monitoring in unanesthetized cats. Am. J. Physiol. Circ. Physiol. 254, H377-H383. doi: 10.1152/ ajpheart.1988.255.6.1-a 
Chen, Y., Wen, C., Tao, G., and Bi, M. (2012). Continuous and noninvasive measurement of systolic and diastolic blood pressure by one mathematical model with the same model parameters and two separate pulse wave velocities. Ann. Biomed. Eng. 40, 871-882. doi: 10.1007/s10439-011-04 $67-2$

Cicchetti, D. V. (1994). Guidelines, criteria, and rules of thumb for evaluating normed and standardized assessment instruments in psychology. Psychol. Assess. 6, 284-290. doi: 10.1037/1040-3590.6.4.284

Cooke, J., Carew, S., Quinn, C., O'connor, M., Curtin, J., O'connor, C., et al. (2013). The prevalence and pathological correlates of orthostatic hypotension and its subtypes when measured using beat-to-beat technology in a sample of older adults living in the community. Age Ageing 42, 709-714. doi: 10.1093/ageing/ aft 112

De Bruïne, E. S., Reijnierse, E. M., Trappenburg, M. C., Pasma, J. H., De Vries, O. J., Meskers, C. G. M., et al. (2017). Standing up slowly antagonises initial blood pressure decrease in older adults with orthostatic hypotension. Gerontology 63, 137-143. doi: 10.1159/000450642

de Bruïne, E. S., Reijnierse, E. M., Trappenburg, M. C., Pasma, J. H., de Vries, O. J., Meskers, C. G. M., et al. (2018). Diminished dynamic physical performance is associated with orthostatic hypotension in geriatric outpatients. J. Geriatr. Phys. Ther. doi: 10.1519/JPT.0000000000000186 [Epub ahead of print].

Dell'Oro, R., Trevano, F. Q., Gamba, P., Ciuffarella, C., Seravalle, G., Mancia, G., et al. (2018). Sympathetic and baroreflex abnormalities in the uncomplicated prediabetic state. J. Hypertens. 36, 1195-1200. doi: 10.1097/HJH. 0000000000001659

Di Rienzo, M., Parati, G., Castiglioni, P., Tordi, R., Mancia, G., Pedotti, A., et al. (2001). Baroreflex effectiveness index: an additional measure of baroreflex control of heart rate in daily life Downloaded from. Am. J. Physiol. Regul. Integr. Comp. Physiol. 280, 744-751.

Di Rienzo, M., Parati, G., Radaelli, A., and Castiglioni, P. (2009). Baroreflex contribution to blood pressure and heart rate oscillations: time scales, timevariant characteristics and nonlinearities. Philos. Trans. R. Soc. A Math. Phys. Eng. Sci. 367, 1301-1318. doi: 10.1098/rsta.2008.0274

Ding, X., Yan, B. P., Zhang, Y.-T., Liu, J., Zhao, N., and Tsang, H. K. (2017). Pulse transit time based continuous cuffless blood pressure estimation: a new extension and a comprehensive evaluation. Sci. Rep. 7:11554. doi: 10.1038/ s41598-017-11507-3

Elgendi, M. (2012). On the analysis of fingertip photoplethysmogram signals. Curr. Cardiol. Rev. 8, 14-25. doi: 10.2174/157340312801215782

Fatisson, J., Oswald, V., and Lalonde, F. (2016). Influence diagram of physiological and environmental factors affecting heart rate variability: an extended literature overview. Heart Int. 11, e32-e40. doi: 10.5301/heartint.5000232

Fonkoue, I. T., Le, N. A., Kankam, M. L., DaCosta, D., Jones, T. N., Marvar, P. J., et al. (2019). Sympathoexcitation and impaired arterial baroreflex sensitivity are linked to vascular inflammation in individuals with elevated resting blood pressure. Physiol. Rep. 7:e14057. doi: 10.14814/phy2.14057

Foo, J. Y. A., and Lim, C. S. (2006). Dual-channel photoplethysmography to monitor local changes in vascular stiffness. J. Clin. Monit. Comput. 20, 221-227. doi: 10.1007/s10877-006-9024-1

Freeman, R., Wieling, W., Axelrod, F. B., Benditt, D. G., Benarroch, E., Biaggioni, I., et al. (2011). Consensus statement on the definition of orthostatic hypotension, neurally mediated syncope and the postural tachycardia syndrome. Clin. Auton. Res. 21, 69-72. doi: 10.1007/s10286-011-0119-5

Frewen, J., Savva, G. M., Boyle, G., Finucane, C., and Kenny, R. A. (2014). Cognitive performance in orthostatic hypotension: findings from a nationally representative sample. J. Am. Geriatr. Soc. 62, 117-122. doi: 10.1111/jgs.1 2592

Frith, J. (2015). Diagnosing orthostatic hypotension: a narrative review of the evidence. Br. Med. Bull. 115, 123-134. doi: 10.1093/bmb/ldv025

Frith, J., Bashir, A. S., and Newton, J. L. (2016). The duration of the orthostatic blood pressure drop is predictive of death. QJM 109, 231-235. doi: 10.1093/ qjmed/hcv126

Gao, M., Olivier, N. B., and Mukkamala, R. (2016). Comparison of noninvasive pulse transit time estimates as markers of blood pressure using invasive pulse transit time measurements as a reference. Physiol. Rep. 4:e12768. doi: 10.14814/ phy2.12768

Hennig, A., and Patzak, A. (2013). Continuous blood pressure measurement using pulse transit time. Somnologie 17, 104-110. doi: 10.1007/s11818-013-0617-x
Ikonomidis, I., Katsanos, S., Triantafyllidi, H., Parissis, J., Tzortzis, S., Pavlidis, G., et al. (2019). Pulse wave velocity to global longitudinal strain ratio in hypertension. Eur. J. Clin. Invest. 49:e13049. doi: 10.1111/eci.13049

Iseli, R., Nguyen, V. T. V., Sharmin, S., Reijnierse, E. M., Lim, W. K., and Maier, A. B. (2019). Orthostatic hypotension and cognition in older adults: a systematic review and meta-analysis. Exp. Gerontol. 120, 40-49. doi: 10.1016/j.exger.2019. 02.017

James, M. A., and Potter, J. F. (1999). Orthostatic blood pressure changes and arterial baroreflex sensitivity in elderly subjects. Age Ageing 28, 522-530. doi: 10.1093/ageing/28.6.522

Jarvis, S. S., VanGundy, T. B., Galbreath, M. M., Shibata, S., Okazaki, K., Reelick, M. F., et al. (2011). Sex differences in the modulation of vasomotor sympathetic outflow during static handgrip exercise in healthy young humans. Am. J. Physiol. Integr. Comp. Physiol. 301, R193-R200. doi: 10.1152/ajpregu.00562. 2010

Juraschek, S. P., Daya, N., Rawlings, A. M., Appel, L. J., Miller, E. R., Windham, B. G., et al. (2017). Association of history of dizziness and long-term adverse outcomes with early vs later orthostatic hypotension assessment times in middle-aged adults. JAMA Intern. Med. 177:1316. doi: 10.1001/jamainternmed. 2017.2937

Juraschek, S. P., Miller, E. R., and Appel, L. J. (2018). Orthostatic hypotension and symptoms in the AASK Trial. Am. J. Hypertens. 31, 665-671. doi: 10.1093/ajh/ hpy010

Kainerstorfer, J. M., Sassaroli, A., Tgavalekos, K. T., and Fantini, S. (2015). Cerebral autoregulation in the microvasculature measured with nearinfrared spectroscopy. J. Cereb. Blood Flow Metab. 35, 959-966. doi: $10.1038 /$ jcbfm. 2015.5

Kamiya, A., Michikami, D., Fu, Q., Niimi, Y., Iwase, S., Mano, T., et al. (2001). Static handgrip exercise modifies arterial baroreflex control of vascular sympathetic outflow in humans. Am. J. Physiol. Integr. Comp. Physiol. 281, R1134-R1139. doi: 10.1152/ajpregu.2001.281.4.R1134

Kocsis, L., Herman, P., and Eke, A. (2006). The modified beer-lambert law revisited. Phys. Med. Biol. 51, N91-N98. doi: 10.1088/0031-9155/51/5/N02

Koivistoinen, T., Kööbi, T., Jula, A., Hutri-Kähönen, N., Raitakari, O. T., Majahalme, S., et al. (2007). Pulse wave velocity reference values in healthy adults aged 26-75 years. Clin. Physiol. Funct. Imaging 27, 191-196. doi: 10.1111/ j.1475-097X.2007.00734.x

Krakow, K., Ries, S., Daffertshofer, M., and Hennerici, M. (2000). Simultaneous assessment of brain tissue oxygenation and cerebral perfusion during orthostatic stress. Eur. Neurol. 43, 39-46. doi: 10.1159/000008127

Lagro, J., Laurenssen, N. C. W. W., Schalk, B. W. M. M., Schoon, Y., Claassen, J. A. H. R. H. R., Olde Rikkert, M. G. M., et al. (2012). Diastolic blood pressure drop after standing as a clinical sign for increased mortality in older falls clinic patients. J. Hypertens. 30, 1195-1202. doi: 10.1097/HJH.0b013e328352b9fd

Laude, D., Baudrie, V., and Elghozi, J. L. (2008). Applicability of recent methods used to estimate spontaneous baroreflex sensitivity to resting mice. Am. J. Physiol. Regul. Integr. Comp. Physiol. 294, 142-150. doi: 10.1152/ajpregu.00319. 2007

Lázaro, J., Gil, E., Orini, M., Laguna, P., and Bailón, R. (2019). Baroreflex sensitivity measured by pulse photoplethysmography. Front. Neurosci. 13:339. doi: 10. 3389/fnins.2019.00339

Lim, J., Pearman, M. E., Park, W., Alkatan, M., Machin, D. R., and Tanaka, H. (2015). Impact of blood pressure perturbations on arterial stiffness. Am. J. Physiol. Regul. Integr. Comp. Physiol. 309, R1540-R1545. doi: 10.1152/ajpregu. 00368.2015

Marchi, A., Bari, V., De Maria, B., Esler, M., Lambert, E., Baumert, M., et al. (2016). Simultaneous characterization of sympathetic and cardiac arms of the baroreflex through sequence techniques during incremental head-up tilt. Front. Physiol. 7:438. doi: 10.3389/fphys.2016.00438

Mehagnoul-Schipper, D. J., Colier, W. N., and Jansen, R. W. (2001). Reproducibility of orthostatic changes in cerebral oxygenation in healthy subjects aged 70 years or older. Clin. Physiol. 21, 77-84. doi: 10.1046/j.1365-2281.2001.00290.x

Mehagnoul-Schipper, D. J., Vloet, L. C. M., Colier, W. N. J. M., Hoefnagels, W. H. L., and Jansen, R. W. M. M. (2000). Cerebral oxygenation declines in healthy elderly subjects in response to assuming the upright position. Stroke 31, 1615-1620. doi: 10.1161/01.STR.31.7.1615

Mol, A., Bui Hoang, P. T. S., Sharmin, S., Reijnierse, E. M., van Wezel, R. J. A., Meskers, C. G. M., et al. (2018a). Orthostatic hypotension and falls in older 
adults: a systematic review and meta-analysis. J. Am. Med. Dir. Assoc. 20, 589.e-597.e. doi: 10.1016/j.jamda.2018.11.003

Mol, A., Reijnierse, E. M., Bui Hoang, P. T. S., van Wezel, R. J. A., Meskers, C. G. M., and Maier, A. B. (2018b). Orthostatic hypotension and physical functioning in older adults: a systematic review and meta-analysis. Ageing Res. Rev. 48, 122-144. doi: 10.1016/j.arr.2018.10.007

Mol, A., Reijnierse, E. M., Trappenburg, M. C., van Wezel, R. J. A., Maier, A. B., and Meskers, C. G. M. (2018c). Rapid systolic blood pressure changes after standing up associate with impaired physical performance in geriatric outpatients. J. Am. Heart Assoc. 7, 1-10. doi: 10.1161/JAHA.118.010060

Mol, A., Woltering, J. H. H., Colier, W. N. J. M., Maier, A. B., Meskers, C. G. M., and van Wezel, R. J. A. (2019). Sensitivity and reliability of cerebral oxygenation responses to postural changes measured with near-infrared spectroscopy. Eur. J. Appl. Physiol. 119, 1117-1125. doi: 10.1007/s00421-019-04101-0

Pasma, J. H., Bijlsma, A. Y., Klip, J. M., Stijntjes, M., Blauw, G. J., Muller, M., et al. (2014). Blood pressure associates with standing balance in elderly outpatients. PLoS One 9:e106808. doi: 10.1371/journal.pone.0106808

Pinna, G. D., La Rovere, M. T., Maestri, R., Mortara, A., Bigger, J. T., and Schwartz, P. J. (2000). Comparison between invasive and non-invasive measurements of baroreflex sensitivity: implications for studies on risk stratification after a myocardial infarction. Eur. Heart J. 21, 1522-1529. doi: 10.1053/euhj.1999.1948

Porta, A., Bassani, T., Bari, V., Tobaldini, E., Takahashi, A. C. M., Catai, A. M., et al. (2012). Model-based assessment of baroreflex and cardiopulmonary couplings during graded head-up tilt. Comput. Biol. Med. 42, 298-305. doi: 10.1016/j. compbiomed.2011.04.019

Ricci, F., Fedorowski, A., Radico, F., Romanello, M., Tatasciore, A., Di Nicola, M., et al. (2015). Cardiovascular morbidity and mortality related to orthostatic hypotension: a meta-analysis of prospective observational studies. Eur. Heart J. 36, 1609-1617. doi: 10.1093/eurheartj/ehv093

Rockwood, M. R. H. H., Howlett, S. E., and Rockwood, K. (2012). Orthostatic hypotension $(\mathrm{OH})$ and mortality in relation to age, blood pressure and frailty. Arch. Gerontol. Geriatr. 54, e255-e260. doi: 10.1016/j.archger.2011.12.009

Saedon, N. I., Zainal-Abidin, I., Chee, K. H., Khor, H. M., Tan, K. M., Kamaruzzaman, S. K., et al. (2016). Postural blood pressure electrocardiographic changes are associated with falls in older people. Clin. Auton. Res. 26, 41-48. doi: 10.1007/s10286-015-0327-5

Saint Martin, M., Sforza, E., Thomas-Anterion, C., Barthélémy, J. C., and Roche, F. (2013). Baroreflex sensitivity, vascular risk factors, and cognitive function in a healthy elderly population: the PROOF cohort. J. Am. Geriatr. Soc. 61, 2096-2102. doi: 10.1111/jgs.12548

Salvi, P. (2017). Pulse Waves, 2nd Edn, Cham: Springer International Publishing.

Scholkmann, F., and Wolf, M. (2013). General equation for the differential pathlength factor of the frontal human head depending on wavelength and age. J. Biomed. Opt. 18:105004. doi: 10.1117/1.JBO.18.10.105004

Silva, L. E. V., Dias, D. P. M., Da Silva, C. A. A., Salgado, H. C., and Fazan, R. (2019). Revisiting the sequence method for baroreflex analysis. Front. Neurosci. 13:17. doi: 10.3389/fnins.2019.00017

Simpson, L. L., Busch, S. A., Oliver, S. J., Ainslie, P. N., Stembridge, M., Steinback, C. D., et al. (2019). Baroreflex control of sympathetic vasomotor activity and resting arterial pressure at high altitude: insight from Lowlanders and Sherpa. J. Physiol. 597, 2379-2390. doi: 10.1113/JP277663

Smolle, K. H., Schmid, M., Prettenthaler, H., and Weger, C. (2015). The accuracy of the $\mathrm{CNAP}^{\circledR}$ device compared with invasive radial artery measurements for providing continuous noninvasive arterial blood pressure readings at a medical intensive care unit: a method-comparison study. Anesth. Analg. 121, 1508-1516. doi: 10.1213/ANE.0000000000000965

Steiner, L. A., Pfister, D., Strebel, S. P., Radolovich, D., Smielewski, P., and Czosnyka, M. (2009). Near-infrared spectroscopy can monitor dynamic cerebral autoregulation in adults. Neurocrit. Care 10, 122-128. doi: 10.1007/ s12028-008-9140-5
Sun, S., Bezemer, R., Long, X., Muehlsteff, J., and Aarts, R. M. (2016). Systolic blood pressure estimation using PPG and ECG during physical exercise. Physiol. Measur. 37, 2154-2169. doi: 10.1088/0967-3334/37/12/2154

Tarumi, T., Dunsky, D. I., Khan, M. A., Liu, J., Hill, C., and Armstrong, K. (2014). Dynamic cerebral autoregulation and tissue oxygenation in amnestic mild cognitive impairment. J. Alzheimers Dis. 41, 765-778. doi: 10.3233/JAD-13 2018

Tarumi, T., and Zhang, R. (2018). Cerebral blood flow in normal aging adults: cardiovascular determinants, clinical implications, and aerobic fitness. J. Neurochem. 144, 595-608. doi: 10.1111/jnc.14234

Timmermans, S. T., Reijnierse, E. M., Pasma, J. H., Trappenburg, M. C., Blauw, G. J., Maier, A. B., et al. (2018). Blood pressure change does not associate with center of pressure movement after postural transition in geriatric outpatients. BMC Geriatr. 18:10. doi: 10.1186/s12877-017-0702-2

Torjesen, A., Cooper, L. L., Rong, J., Larson, M. G., Hamburg, N. M., Levy, D., et al. (2017). Relations of arterial stiffness with postural change in mean arterial pressure in middle-aged adults: the framingham heart study. Hypertension 69, 685-690. doi: 10.1161/HYPERTENSIONAHA.116.08116

van der Velde, N., van den Meiracker, A. H., Stricker, B. H. C., and van der Cammen, T. J. M. (2007). Measuring orthostatic hypotension with the Finometer device: is a blood pressure drop of one heartbeat clinically relevant? Blood Press. Monit. 12, 167-171. doi: 10.1097/mbp.0b013e3280b0 $83 \mathrm{bd}$

van Lieshout, J. J., Pott, F., Madsen, P. L., van Goudoever, J., and Secher, N. H. (2001). Muscle tensing during standing. Stroke 32, 1546-1551. doi: 10.1161/01. STR.32.7.1546

van Wijnen, V. K., Finucane, C., Harms, M. P. M., Nolan, H., Freeman, R. L., Westerhof, B. E., et al. (2017). Noninvasive beat-to-beat finger arterial pressure monitoring during orthostasis: a comprehensive review of normal and abnormal responses at different ages. J. Intern. Med. 282, 468-483. doi: 10.1111/joim. 12636

Verwoert, G. C., Mattace-Raso, F. U. S., Hofman, A., Heeringa, J., Stricker, B. H. C., Breteler, M. M. B., et al. (2008). Orthostatic hypotension and risk of cardiovascular disease in elderly people: the rotterdam study. J. Am. Geriatr. Soc. 56, 1816-1820. doi: 10.1111/j.1532-5415.2008.01946.x

Wakeham, D. J., Lord, R. N., Talbot, J. S., Lodge, F. M., Curry, B. A., Dawkins, T. G., et al. (2019). Upward resetting of the vascular sympathetic baroreflex in middle-aged male runners. Am. J. Physiol. Circ. Physiol. 317, H181-H189. doi: 10.1152/ajpheart.00106.2019

Wang, Y., Liu, Z., and Ma, S. (2018). Cuff-less blood pressure measurement from dual-channel photoplethysmographic signals via peripheral pulse transit time with singular spectrum analysis. Physiol. Measur. 39:25010. doi: 10.1088/13616579/aa996d

Zanotto, T., Mercer, T. H., van der Linden, M. L., Traynor, J. P., Petrie, C. J., Doyle, A., et al. (2018). Baroreflex function, haemodynamic responses to an orthostatic challenge, and falls in haemodialysis patients. PLoS One 13:e0208127. doi: 10. 1371/journal.pone.0208127

Ziegler, M. G. (2018). Atherosclerosis and blood pressure variability. Hypertension 71, 403-405. doi: 10.1161/hypertensionaha.117.10481

Conflict of Interest: The authors declare that the research was conducted in the absence of any commercial or financial relationships that could be construed as a potential conflict of interest.

Copyright (C) $2020 \mathrm{Mol}$, Maier, van Wezel and Meskers. This is an open-access article distributed under the terms of the Creative Commons Attribution License (CC BY). The use, distribution or reproduction in other forums is permitted, provided the original author(s) and the copyright owner(s) are credited and that the original publication in this journal is cited, in accordance with accepted academic practice. No use, distribution or reproduction is permitted which does not comply with these terms. 